\title{
The added value to global model projections of climate change by dynamical downscaling: A case study over the continental U.S. using the GISS-ModelE2 and WRF models
}

\author{
P. N. Racherla, ${ }^{1,2}$ D. T. Shindell, ${ }^{1,2}$ and G. S. Faluvegi ${ }^{1,2}$ \\ Received 9 May 2012; revised 20 September 2012; accepted 26 September 2012; published 27 October 2012.
}

[1] Dynamical downscaling is being increasingly used for climate change studies, wherein the climates simulated by a coupled atmosphere-ocean general circulation model (AOGCM) for a historical and a future (projected) decade are used to drive a regional climate model (RCM) over a specific area. While previous studies have demonstrated that RCMs can add value to AOGCM-simulated climatologies over different world regions, it is unclear as to whether or not this translates to a better reproduction of the observed climate change therein. We address this issue over the continental U.S. using the GISS-ModelE2 and WRF models, a state-of-the-science AOGCM and RCM, respectively. As configured here, the RCM does not effect holistic improvement in the seasonally and regionally averaged surface air temperature or precipitation for the individual historical decades. Insofar as the climate change between the two decades is concerned, the RCM does improve upon the AOGCM when nudged in the domain proper, but only modestly so. Further, the analysis indicates that there is not a strong relationship between skill in capturing climatological means and skill in capturing climate change. Though additional research would be needed to demonstrate the robustness of this finding in AOGCM/RCM models generally, the evidence indicates that, for climate change studies, the most important factor is the skill of the driving global model itself, suggesting that highest priority should be given to improving the long-range climate skill of AOGCMs.

Citation: Racherla, P. N., D. T. Shindell, and G. S. Faluvegi (2012), The added value to global model projections of climate change by dynamical downscaling: A case study over the continental U.S. using the GISS-ModelE2 and WRF models, J. Geophys. Res., 117, D20118, doi:10.1029/2012JD018091.

\section{Background and Objectives}

[2] Although atmosphere-ocean general circulation models (AOGCMs) continue to be the primary source of information on future climate change, many end-users from the public- and private-sectors do not use such information as is, but prefer, instead, a transformed version at higher horizontal resolutions. The primary motivation for effecting such a transformation - generally referred to as downscaling - is to extract information in areas characterized by features such as complex topography, urban centers, differing vegetation/ soil types, and land-sea contrasts that the AOGCM does not resolve.

\footnotetext{
${ }^{1}$ Center for Climate Systems Research, Earth Institute, Columbia University, New York, New York, USA.

${ }^{2}$ NASA Goddard Institute for Space Studies, New York, New York, USA.

Corresponding author: P. N. Racherla, Center for Climate Systems Research, Earth Institute, Columbia University, Armstrong Hall, 2880 Broadway, New York, NY 10025, USA.

(pavan.racherla+jpub@gmail.com)

C2012. American Geophysical Union. All Rights Reserved. 0148-0227/12/2012JD018091
}

[3] The two most widely used downscaling methods traditionally have been statistical and dynamical [Wilby and Wigley, 1997]. In statistical downscaling, a model is developed for the region of interest, which (statistically) relates large-scale climate variables to regional and local variables under historical conditions; then, the output of a global climate model is input to this statistical model to approximate the corresponding regional and local climate. For example, the downscaled CMIP3 (Coupled Model Inter-comparison Project [Meehl et al., 2007], phase 3) projections available at http://gdo-dcp.ucllnl.org/downscaled_cmip3_projections/ were developed using this method.

[4] In dynamical downscaling, a regional climate model (RCM) is integrated over the region of interest, constrained by a global climate model at the lateral boundaries. The North American Regional Climate Change Assessment Program (NARCCAP - http://www.narccap.ucar.edu/) is one such project that uses dynamical downscaling. When constrained by a global reanalysis at the lateral boundaries, RCMs have been shown to simulate more realistically nearsurface winds and temperatures over complex terrain and coastlines, as well as mesoscale processes and variability, particularly when the RCM's large-scale variability is constrained in the domain proper [e.g., see Feser et al., 2011]. 
[5] In addition to the dynamical downscaling method described above, there exists the global-through-local nested, online-coupled meteorology and chemistry model that downscales not just dynamics, but also gases, aerosols, and other parameters, while treating physical processes in a largely consistent manner on all scales [e.g., see Jacobson, 2001a, 2001b]. In contrast, most RCMs used in dynamical downscaling have offline aerosol profiles that may or may not be consistent with the upscale (AOGCM) information, and, often, treat gas-phase chemistry, aerosol microphysics, and aerosol-cloud interactions in a highly simplified manner [Zhang, 2008]. Consequently, while the global-throughlocal nested model treats climate-chemistry-aerosol-cloudradiation feedbacks in a consistent manner, dynamical downscaling does not, and this has important implications for regional climate change projections [Brasseur and Roeckner, 2005; Jacobson, 2008]. The object of scrutiny hereafter is the dynamical downscaling method.

[6] Based on the degree of influence of real-world observations, Castro et al. [2005] classified dynamical downscaling applications into 4 types: numerical weather prediction (1); regional climate simulations driven by global reanalyses (2), atmosphere-only general circulation models (3), and AOGCMs (4). In type 1 the memory of the allimportant initial conditions containing atmospheric observations is not lost due to the short-term nature of the model integration. In type 2 that memory is lost, but the periodically enforced lateral boundary conditions do contain atmospheric observations. In type 3 the real-world influence comes indirectly via the observed ocean boundary conditions driving the atmosphere-only general circulation model (e.g., monthly mean sea surface temperatures). It is only in type 4 , i.e., the kind used in projects like NARCCAP, that such real-world constraints are completely absent.

[7] Consequently, one cannot make a generalized argument for the value added by dynamical downscaling across application types. This subtle, but important, point is not stated clearly in many studies on the subject, including the one cited earlier by Feser et al. [2011]. In this context, it is worth mentioning that all the RCMs involved in NARCCAP were evaluated under type 2 configuration (see http:// www.narccap.ucar.edu/about/index.html), despite the fact that they are used eventually to perform type 4 dynamical downscaling.

[8] The proliferating use of type 4 dynamical downscaling for climate impact applications hinges on the expectation that a RCM shall improve upon the quality of the AOGCM's future climate projection over the region of interest, just as it did in the historical case [e.g., see Liang et al., 2006]. Needless to say, this presupposes that the future (projected) climate driving the RCM is credible. That is, it is assumed that AOGCMs have the ability to predict a climatic sequence from the past or present to a future-day, simulating not only the overall response to postulated anthropogenic forcings, but also natural variations - of the kind that have been observed - on inter-annual to multidecadal timescales. In short, this is a presupposition about the climate-sensitivity and -variability skills of AOGCMs, an evaluation of which is not the focus of the current study.

[9] Another presupposition is that historical climate biases transfer linearly into the future, and, therefore, can be accounted for straightforwardly when examining, for example, differences between the future and historical climates. Although Liang et al. [2008] demonstrated, contrary to this popular notion, that future climate projections by an AOGCM or RCM are very sensitive to the existence of historical climate biases, they nevertheless concluded that "if the driving GCM reasonably simulates the circulation governing the regional present climate, the nested RCM that offers skill enhancement also implies higher credibility in downscaling the future climate projection." Thus, it is being implied that the higher the quality of the historical AOGCM climate, the higher the credibility of the future climate projection, which, in turn, increases the likelihood of the RCM adding value to it. We take the liberty of rephrasing this chain of reasoning as: there is a (strong) relationship between the quality of the historical (e.g., the 1970s) climate and climate change (e.g., the 2000s minus the 1970s) in an AOGCM or RCM.

[10] While the above reasoning is intuitively appealing, it is possible that there is no correlation between the quality of the historical climate and climate change in either the AOGCM or the RCM. That is to say, a region with small historical climate biases might nonetheless display a contrarian climate change signal vis-a-vis that observed, and vice versa. However, because the cited study and indeed virtually all previous studies focused on future, not historical, climate change, it is hard to discern whether or not this is true.

[11] With these issues in the background, the objectives of this case study are to explore whether: (1) dynamical downscaling adds value to AOGCM simulations of historical climate change; and, (2) a correlation exists between the quality of the downscaled historical climate and climate change. The rest of the article is organized as follows: section 2 has the methods; section 3, the results; and section 4, a discussion and the conclusions.

\section{Methods}

[12] We used the Goddard Institute for Space Studies (GISS) model for physical understanding of compositionclimate interactions and impacts [Shindell et al., 2006] to simulate the global climates representative of the time slices December 1967 through December 1978 and December 1994 through December 2005. The model incorporates gasphase, sulfate, black carbon, nitrate, and secondary organic aerosol chemistry within the GISS-ModelE2 GCM [Schmidt et al., 2006]. Model updates are described in Shindell et al. [2012] and references therein. Hereafter, we shall simply refer to this model as ModelE2. It has a horizontal grid increment of $2^{\circ}$ latitude by $2.5^{\circ}$ longitude and 40 vertical hybrid sigma layers from the surface to $0.1 \mathrm{hPa}$. The dynamical time step is fixed at $30 \mathrm{~min}$. Using the anthropogenic and natural forcings described in Schmidt et al. [2011], transient climate simulations were performed and 3-hourly surface/atmospheric fields archived for the aforementioned time slices. These fields were then modified suitably for the input-preprocessing system of the of the Weather Research \& Forecasting (WRF) model ("advanced research" version 3.3, released in April 2011) [Skamarock et al., 2008].

[13] Figure 1 shows the WRF domain, which covers the entire continental U.S. and Mexico as well as much of Canada, including the Hudson Bay; there is substantial oceanic coverage east and west of these land regions. There are 216 cells in the west-east direction and 126 in the south-north spaced 


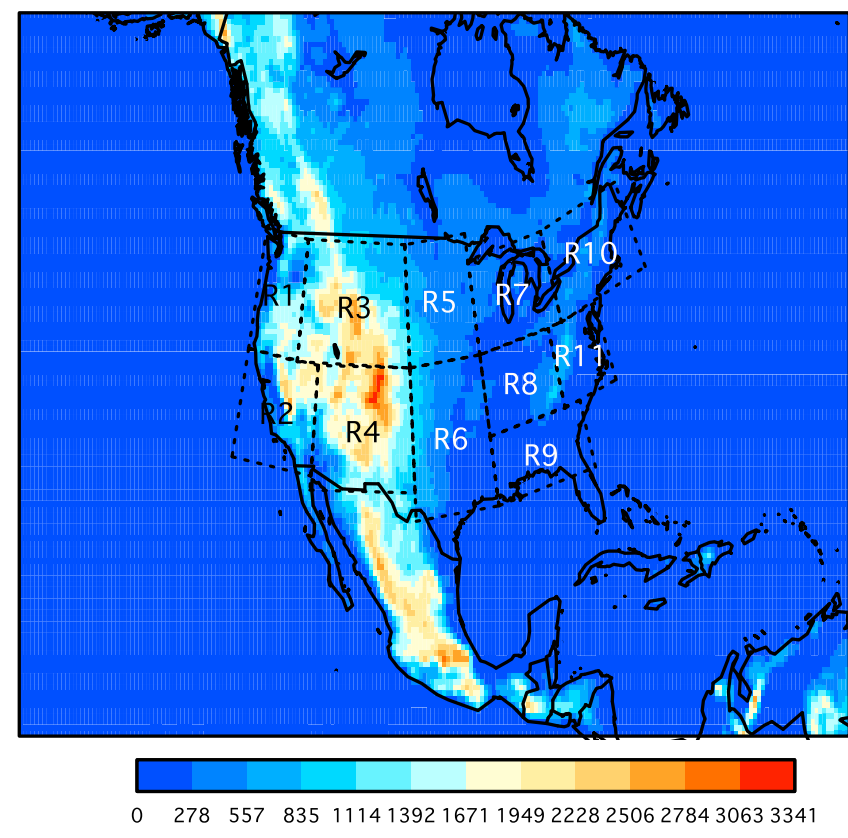

Figure 1. The WRF model domain and underlying topography (m); the map projection is Lambert conical conformal. Shown also are 11 (R1, R2, $\cdots \mathrm{R} 11)$ continental U.S. regions over which the evaluation is focused.

$45 \mathrm{~km}$ apart $\left(\approx 0.41^{\circ}\right.$ in the midlatitudes $)$, with the true scale at $30^{\circ} \mathrm{N}$ and $60^{\circ} \mathrm{N}$. Consequently, the grid spacing ratio between ModelE2 and WRF (at the true scale) is $\approx 6$ and 5 in the west-east and south-north directions, respectively. In the vertical, there are 45 terrain-following levels from the surface to $10 \mathrm{hPa}$; they are spaced closer together within the planetary boundary layer and again near the model top. These levels are not consistent with ModelE2's; therefore, ModelE2's vertical fields are mapped to them using the procedure described in Chuang et al. [2001].

[14] We utilized an adaptive dynamical time step in the WRF domain, anchored around an initial value $\left(\Delta t_{i}\right)$ of $4.5 \mathrm{~min}$. The target maximum Courant number $\left(c_{t}\right)$ was set to be 1.2. At any given time, WRF incorporates the adaptive time step by computing the maximum domain-wide Courant number for all the velocity components (i.e., $u, v$, and $w$ ): if this is less than $c_{t}$, then the time step is increased by $5 \%$; else, it is reduced by $25 \%$ to insure numerical stability. The lowerand upper-bound on the adaptive time step are $0.5 \Delta t_{i}$ and $3 \Delta t_{i}$, respectively.

[15] At each of the 4 boundaries of the WRF domain there is a buffer zone 9 cells wide with the outermost row/column completely specified by ModelE2 and the inner 8 relaxed exponentially toward WRF. The exponential relaxation which results in a smoother behavior in the buffer zone - is achieved by multiplying the linear relaxation functions in the original scheme of Davies and Turner [1977] by an exponential function. Specifically, we used an inverse length scale [Skamarock et al., 2008] (in grid lengths) of $\frac{1}{3}$. There is scope for further optimization with regards these settings [e.g., see Liang et al., 2001].

[16] Toward selecting a suite of physical parameterizations in the WRF model that work best with the ModelE2 inputs, we began with those used by the National Center for
Atmospheric Research (NCAR) for their (10-30 km grid increment) regional climate runs over North America [see Wang et al., 2010]. We then performed several test runs using the ModelE2 inputs (corresponding to one historical summer and winter), incorporating other parameterizations appropriate to a $45 \mathrm{~km}$ grid increment. Finally, the simulated surface air temperature and precipitation (PRCP) were assessed for their realism by comparing them against the CRU data (described shortly below). Based on these tests, the following selections were made: Kain-Fritsch (cumulus) [Kain, 2004]; WRF single-moment 5-class (microphysics) [Hong et al., 2004; Hong and Lim, 2006]; CAM (shortwave and longwave radiation) [Collins et al., 2004]; Noah (land/surface) [Chen and Dudhia, 2001]; Yonsei University (planetary boundary layer) [Hong et al., 2006]; and MM5 similarity theory (surface layer) [Skamarock et al., 2008]. Sea surface temperatures and sea-ice were updated at the same 3-hourly frequency as the lateral boundary conditions using the ModelE2 data.

[17] Four WRF simulations were performed using the above configuration (Table 1). Note the use of analysisnudging in simulations 2 and 4 . In these, the free-atmospheric zonal and meridional-wind, temperature, and humidity are nudged in the domain proper by ModelE2 using a moderate nudging coefficient of $3 \times 10^{-4}$. Our objective here was not so much to determine an optimal nudging configuration. Rather, it was to develop a general understanding on the pros and cons of suppressing large-scale RCM variability in the context of type 4 dynamical downscaling. Note that the case of spectral-nudging [von Storch et al., 2000], wherein only the largest wavelengths are nudged, lies somewhere between the un-nudged and analysis-nudging (the entire wavelength spectrum is nudged) ones.

[18] The simulated climate (D1 and D2 decades) and climate change (D2 minus D1 decades) over the continental U.S. were evaluated using the $0.5^{\circ}$ resolution monthly analysis (version 3.1; 1901-2009) of daily mean surface air temperature (TAVE hereafter) and PRCP published by the Climate Research Unit (CRU) of the University of East Anglia [New et al., 1999, 2000]. Note that TAVE is defined simply as the arithmetic mean of the observed daily minimum and -maximum surface air temperature. We did not use the minimum (maximum) values by themselves because their trends are overestimated (underestimated) depending on the siting quality (station exposure conditions), whereas the TAVE trends are relatively insensitive to the same [Fall et al., 2011]. Also, because of the greater station density

Table 1. The Four WRF Simulations Performed Using the ModelE2 Data ${ }^{\mathrm{a}}$

\begin{tabular}{ccc}
\hline Simulation & Timeframe & Analysis-Nudging? \\
\hline 1 & December, 1967 - December, 1978 & no \\
2 & December, 1994 - December, 2005 & yes \\
3 & December, 1967 - December, 1978 & no \\
4 & December, 1994 - December, 2005 & yes \\
\hline
\end{tabular}

${ }^{\mathrm{a}}$ The last column indicates whether analysis-nudging (by ModelE2 in the domain proper) is used (yes) or not (no) in that simulation. The default suite of diagnostics in WRF were saved monthly, whereas, surface air temperature and precipitation were saved every hour. Following standard protocol, the first year of each simulation was dropped from the analysis, which left 10 years of data: Dec/1968 - Dec/1978 (D1 decade) and Dec/1995 - Dec/ 2005 (D2 decade). 


\begin{tabular}{r|cccc|ccc|c|c|c|c|c|}
\multicolumn{3}{c}{} & \multicolumn{3}{c}{ ModelE2i (D1) } & \multicolumn{4}{c}{ WRF, un-nudged (D1) } & \multicolumn{3}{c|}{ WRF, nudged (D1) } \\
R11 & 1.2 & 0.8 & 1.2 & 0.9 & 2.2 & 2.0 & 2.6 & 2.1 & 1.1 & 1.2 & 2.3 & 1.1 \\
R10 & 1.3 & 1.6 & 0.7 & 0.9 & 2.2 & 2.6 & 2.9 & 1.5 & 2.0 & 2.3 & 2.4 & 1.0 \\
R9 & 0.7 & 0.5 & 1.8 & 0.4 & 2.2 & 2.0 & 1.9 & 2.1 & 0.8 & 1.5 & 2.3 & 0.8 \\
R8 & 0.6 & 0.4 & 1.8 & 0.9 & 2.9 & 2.5 & 3.1 & 3.1 & 0.4 & 2.0 & 2.9 & 1.1 \\
R7 & 0.8 & 1.4 & 0.9 & 0.5 & 3.7 & 2.9 & 3.0 & 2.1 & 2.3 & 3.0 & 2.5 & 1.3 \\
R6 & 0.8 & 0.9 & 2.6 & 0.7 & 1.8 & 1.8 & 2.8 & 2.2 & 1.0 & 3.2 & 2.5 & 0.7 \\
R5 & 2.6 & 1.1 & 1.5 & 0.4 & 1.7 & 3.2 & 2.9 & 1.6 & 1.0 & 7.2 & 2.8 & 0.7 \\
R4 & 2.0 & 2.4 & 3.6 & 1.6 & 0.9 & 1.1 & 2.1 & 1.0 & 2.1 & 2.5 & 2.6 & 0.8 \\
R3 & 2.3 & 2.0 & 3.6 & 1.7 & 2.2 & 1.7 & 2.5 & 1.1 & 2.5 & 6.8 & 4.1 & 1.5 \\
R2 & 2.0 & 2.6 & 4.0 & 2.5 & 1.3 & 1.3 & 2.1 & 1.6 & 2.2 & 2.6 & 3.2 & 1.6 \\
R1 & 1.1 & 1.6 & 2.8 & 1.4 & 1.2 & 1.1 & 1.7 & 1.0 & 2.0 & 3.6 & 3.4 & 1.1 \\
\hline
\end{tabular}

\begin{tabular}{r|cccc|ccc|c|c|c|c|c|} 
R11 & 1.2 & 1.1 & 1.0 & 0.9 & 3.2 & 1.7 & 2.4 & 2.2 & 1.2 & 0.9 & 2.3 & 1.1 \\
R10 & 0.9 & 2.1 & 0.7 & 0.8 & 3.0 & 2.4 & 2.6 & 1.8 & 1.4 & 1.9 & 2.4 & 1.0 \\
R9 & 0.7 & 0.4 & 1.3 & 0.3 & 2.7 & 1.7 & 1.8 & 2.4 & 1.0 & 1.1 & 2.0 & 1.1 \\
R8 & 0.8 & 0.8 & 1.4 & 0.8 & 4.5 & 2.1 & 2.9 & 3.2 & 0.6 & 1.4 & 2.8 & 1.3 \\
R7 & 1.0 & 1.8 & 0.7 & 0.7 & 4.5 & 2.5 & 2.9 & 2.1 & 2.3 & 2.7 & 2.5 & 1.4 \\
R6 & 0.6 & 0.6 & 1.9 & 0.5 & 2.2 & 1.4 & 2.3 & 2.1 & 0.8 & 1.7 & 2.1 & 0.8 \\
R5 & 1.1 & 1.7 & 1.2 & 0.5 & 2.9 & 1.9 & 2.4 & 1.2 & 1.9 & 5.8 & 2.4 & 0.7 \\
R4 & 2.9 & 2.6 & 2.5 & 1.3 & 1.2 & 0.9 & 1.6 & 1.1 & 2.8 & 2.3 & 1.8 & 0.8 \\
R3 & 2.5 & 2.1 & 3.1 & 1.3 & 2.6 & 1.7 & 2.0 & 1.1 & 3.4 & 6.5 & 3.5 & 1.2 \\
R2 & 2.6 & 2.9 & 3.8 & 2.4 & 1.6 & 1.3 & 1.9 & 1.8 & 3.1 & 3.1 & 2.8 & 1.7 \\
R1 & 1.6 & 1.8 & 2.5 & 1.3 & 1.7 & 1.6 & 1.4 & 1.1 & 2.8 & 4.2 & 3.1 & 1.0 \\
\hline
\end{tabular}

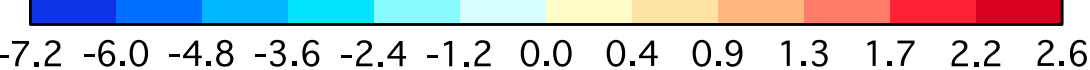

Figure 2. Seasonal-mean (D1/D2 decades) daily average surface air temperature biases (degC; ModelE2/ WRF minus CRU) averaged over the 11 regions shown in Figure 1. Superimposed are the regional-mean absolute biases $(\mu)$. The biases were computed after interpolating the ModelE2 and WRF data on to the $0.5^{\circ}$ resolution CRU grid.

and flatter terrain over the eastern U.S. vis-a-vis the west, the CRU analysis is of a higher quality therein - a point worth emphasizing.

\section{Results}

[19] We begin by examining the downscaled TAVE and PRCP biases for the D1/D2 decades (Figures 2 and 3), focussing primarily on features common to both decades.
Note that the horizontal grid increment of WRF used here is slightly finer than CRU's, whereas ModelE2's is 4-5 times coarser. The rationale behind reducing ModelE2's output onto the CRU grid, prior to computing regional-mean biases, is to evaluate whether WRF, as configured, adds value above and beyond mere interpolation of the input - this is akin to the AV1 (added value, component 1) concept defined in di Luca et al. [2011]. However, it should be made clear that this is by no means an evaluation of ModelE2 itself.

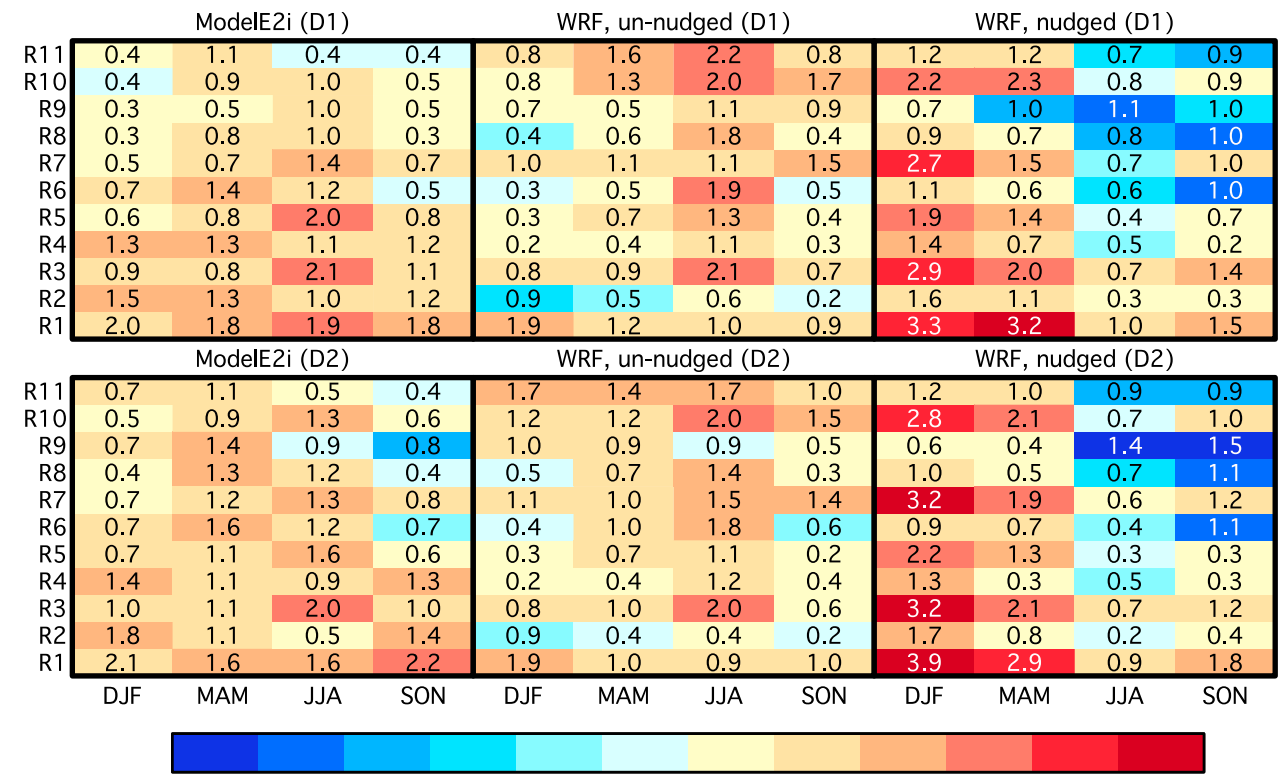

$\begin{array}{lllllllllllll}-1.4 & -1.2 & -1.0 & -0.7 & -0.5 & -0.2 & 0.0 & 0.6 & 1.3 & 1.9 & 2.5 & 3.1 & 3.8\end{array}$

Figure 3. As in Figure 2 except for precipitation $\left(\mathrm{mm} \mathrm{d}^{-1}\right)$. 


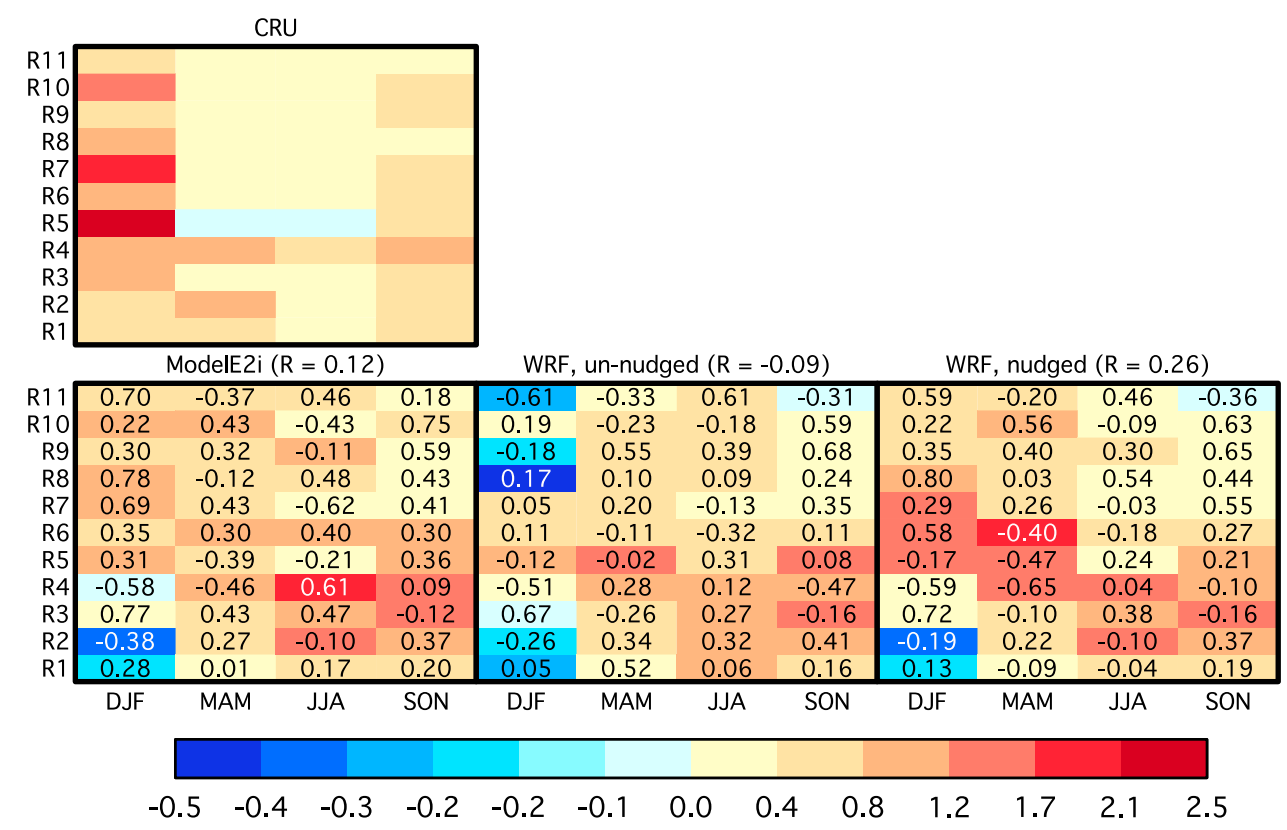

Figure 4. Seasonal-mean daily average surface air temperature changes (degC; D2 minus D1 decades) averaged over the 11 regions shown in Figure 1. The changes were computed after interpolating the ModelE2 and WRF data on to the $0.5^{\circ}$ resolution CRU grid. For the ModelE2/WRF panels, superimposed are the regional Pearson's correlation coefficients $(r)$, computed with respect to the CRU-analyzed change at a $0.5^{\circ}$ resolution; also included in parentheses in the panel titles are the overall Pearson's correlation coefficients $(R)$, computed with respect to the CRU changes as shown in the top row.

To avoid confusion, we distinguish such interpolated ModelE2 data by using the suffix $i$ (i.e., ModelE2i).

[20] The regional-mean absolute bias $(\mu)$ values for TAVE in ModelE2 $\mathrm{i}$ are generally within $\pm 3 \operatorname{degC}$, with the mean bias being negative more often than not for most regions and seasons (Figure 2). Seasonally, the $\mu$ values are largest during summer, wherein there is a cold bias over almost all regions, especially over the western regions (R1-R4). The only systematic warm bias occurs over the central-eastern regions (R5-R11) during spring. It is evident that, overall, there is not much value added by WRF, whether nudged in the domain proper by ModelE2 or not. All the same, the biases are generally smaller when WRF is nudged than when it is not. The exception to this is during spring and summer, when the nudged WRF simulations have a noticeably larger cold bias (up to $-7 \mathrm{degC}$ ) over the north west-central regions (R3/R5).

[21] For PRCP, there is a wet bias in ModelE2i (Figure 3). As with TAVE, the $\mu$ values are regionally larger over the west; seasonally, during spring and summer. The biases over the west are reduced in WRF (except during summer) when not nudged in the domain proper by ModelE2; this is also true over the central regions (R5/R6). At the same time, the biases increase noticeably over the east (R7-R11). It can be seen that nudging is consistently beneficial only during summer, when precipitation is mostly convective; during winter, when precipitation is mostly stratiform, nudging seems to amplify the upscale biases.

[22] We turn our attention now to the downscaled changes in TAVE and PRCP between the D1 and D2 decades (Figures 4 and 5). The most visible CRU-analyzed ("observed" hereafter) TAVE changes are the wintertime increases
(0.4-2.5 degC) throughout the continental U.S., particularly over the north central-east regions (R5, R7, and R10) where they exceed $1 \mathrm{degC}$. More intriguing, however, are the muted increases $(<0.4 \mathrm{degC})$ over the central-eastern regions during spring and summer. Some explanations for these changes have been offered, for example, in Portmann et al. [2009].

[23] The close resemblance between the spatiotemporal pattern of TAVE change in ModelE2i and WRF, especially when nudged in the domain proper by ModelE2, is quite striking. The one notable exception to this is the cooling over the southeast and mid-Atlantic regions (R8, R9, and R11) when WRF is not nudged. And because ModelE2 $i$ itself does not capture the spatiotemporal pattern of observed change that well — as indicated by the low overall correlation coefficient $(R)$ of 0.12 - it is not surprising that WRF does not either. Nevertheless, when WRF is nudged, the $R$ value is slightly improved (0.26) with respect to ModelE2i. The $R$ value is actually degraded $(-0.09)$ by WRF when not nudged.

[24] The most visible observed PRCP changes $\left(>0.5 \mathrm{~mm} \mathrm{~d}^{-1}\right.$ in absolute terms) have occurred over the Southeast U.S. (R9), wherein there are decreases in spring/winter and increases in summer/fall; the remaining changes are generally within $\pm 0.1 \mathrm{~mm} \mathrm{~d}^{-1}$. Evidently, the observed changes over the Southeast are not reproduced well in either ModelE2i or WRF. As with TAVE, when WRF is nudged, there is an improvement in the $R$ value with respect to ModelE2 $\mathrm{i}$ (from -0.10 to 0.12 ); and, when not nudged, a marked degradation $(-0.42)$.

[25] Earlier, we put forth the hypothesis that a strong association may not exist between the quality of the simulated (upscale or downscaled) historical climates for two 


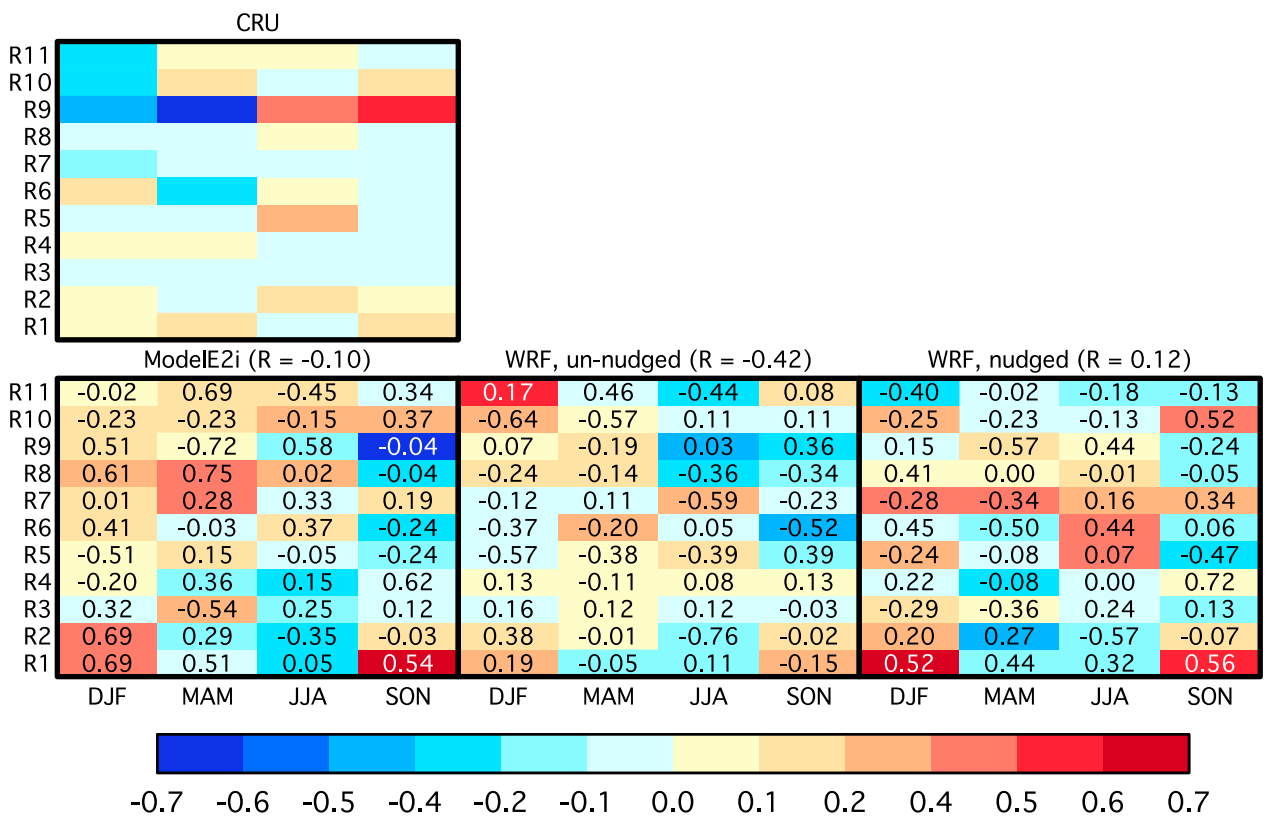

Figure 5. As in Figure 4 except for precipitation $\left(\mathrm{mm} \mathrm{d}^{-1}\right)$.

individual decades and the climate change between the two decades. Toward verifying that hypothesis, we determined the Spearman rank-correlation coefficient $(-1 \leq \rho \leq 1)$ between the regional-mean absolute biases $(\mu)$ shown in Figure 2 (3) and the regional Pearson correlations $(r)$ shown in Figure 4 (5). For this exercise, however, we replaced mean absolute biases with mean normalized absolute biases $\left(\mu_{n}\right)$, and Pearson correlations $(-1 \leq r \leq 1)$ with distance correlations $\left(0 \leq r_{d} \leq 1\right)$ [Székely et al., 2007]. Here, $\mu_{n}$ is a measure of the quality of the simulated climate over a region ( $\mu_{n} \rightarrow+\infty$ being poor quality; $\mu_{n}=0$, the highest), whereas $r_{d}$ is a measure of the quality of the simulated climate change ( $r_{d}=0$ being the lowest quality; $r_{d}=1$, the highest).

[26] Because rank-correlation measures quantify the direction of association between two variables, we shall see a $\rho$ value closer to -1 if $\mu_{n}$ decreases as $r_{d}$ increases, and a $\rho$ value closer to +1 if $\mu_{n}$ increases as $r_{d}$ increases. If there is no such tendency - which is our expectation - $\rho$ shall be closer to zero.

[27] The results of the above exercise are summarized in Table 2. It shows that the $\rho$ values are within \pm 0.25 - that is closer to zero than \pm 1 - for both WRF (whether nudged or not) and ModelE2i. This indeed confirms that there is very little association between the quality of the historical climate and climate change in AOGCMs or RCMs. Although it is difficult to make a definitive comment with just the existing simulations, we conclude that the changes are driven by processes other than those that dominate the creation of climatological means.

\section{Discussion and Conclusions}

[28] With respect to the ModelE2-simulated climates for the time slices Dec/1968 - Dec/1978 and Dec/1995 Dec/2005, it is indeed hard to discern holistic improvement after dynamical downscaling using WRF, whether nudged in the domain proper by ModelE2 or not. A similarly poor performance over the North American region was documented recently by $X u$ and Yang [2012], who used the same WRF version employed in the current study (with a different physical configuration) to downscale a 30-year (historical) climatology simulated by the NCAR Community Atmosphere Model. Our conclusion above is of course subject to revision depending on the exact configuration of WRF, particularly the suite of physical parameterizations chosen. Also, we examined only seasonally and regionally averaged surface air temperatures and precipitation, and it is possible that one might see noteworthy improvements in the 95th-percentiles etc., as shown by di Luca et al. [2011] for RCM simulations driven by global reanalyses.

[29] More germane to the objectives of the current case study, however, is the finding that the seasonally and regionally averaged surface air temperature and precipitation changes (between the Dec/1995 - Dec/2005 and Dec/1968 Dec/1978 time slices) correlated better with that observed after downscaling, only when WRF was nudged in the domain proper by ModelE2. It is not surprising, then, that the gain overall is somewhat modest ( $R$ increased from 0.12 to 0.26 and -0.10 to 0.12 , corresponding to surface air temperature and precipitation, respectively - see Figures 4 and 5 ), because the RCM is constrained to stay within specified

Table 2. The Spearman Rank-Correlation Coefficient ( $\rho$ ) Between the Regional-Mean Normalized Absolute Biases From Figures 2 and 3 for the D1 and D2 Decades, Respectively and the Regional "Distance" Correlations From Figures 4 and $5^{\mathrm{a}}$

\begin{tabular}{lrrrrr}
\hline & \multicolumn{2}{c}{$\rho$ (TAVE) } & & \multicolumn{2}{c}{$\rho$ (PRCP) } \\
\cline { 2 - 3 } \cline { 6 - 6 } & \multicolumn{1}{c}{$\mathrm{D} 1$} & \multicolumn{1}{c}{$\mathrm{D} 2$} & & \multicolumn{1}{c}{ D1 } & \multicolumn{1}{c}{ D2 } \\
\hline WRF, un-nudged & -0.10 & -0.14 & & -0.20 & -0.18 \\
WRF, nudged & 0.11 & 0.16 & & 0.21 & 0.22 \\
ModelE2i & 0.22 & 0.19 & & -0.15 & -0.15 \\
\hline
\end{tabular}

${ }^{\text {a}}$ Please see the final 3 paragraphs of section 3 for an explanation. 
bounds of the AOGCM when nudged at each grid point. Clearly, for regional climate change studies to truly benefit from dynamical downscaling, sound upscale information is a must - a point also well made in Pielke and Wilby [2012].

[30] Are AOGCMs currently able, then, to provide such information? This has in fact been examined in several recent studies (e.g., see Wilby [2010] and Kundzewicz and Stakhiv [2010] for an overview), and there is a general agreement that, while multiseasonal and decadal hindcasts are much improved now on the large-scale, the reproduction of longerterm (multidecadal) regional trends and variations remains a significant challenge. As argued by Wilby and Dessai [2010], however, whether or not this has an important bearing for an application, depends ultimately on whether one approaches climate change from a mitigation (scenario-driven, top-down) or adaptation (scenario-neutral, bottom-up) perspective.

[31] Returning to the findings of the current case study, we were surprised to see the extent to which the correlation deteriorated between the simulated and observed changes after downscaling, when WRF was not nudged in the domain proper by ModelE2 $(R$ decreased from 0.12 to -0.09 and -0.10 to -0.42 , corresponding to surface air temperature and precipitation, respectively). This is likely related to the internal variability in RCMs when they are integrated over large (continental-sized) domains [Laprise et al., 2008; Lucas-Picher et al., 2008], which makes it hard to distinguish between the effects of decadal variability and decadal forcing when differences between two 10-year time slices are examined.

[32] Longer (multidecadal) simulations might help isolate the "signal" (climate change) from the "noise" (internal variability). That being said, it is worth noting that, notwithstanding today's super-computing resources, multidecadal RCM simulations are quite expensive to perform. Perhaps, this is one reason why virtually almost all AOGCM-RCM climate change studies continue with the experimental setup of downscaling one historical decade and one future decade, and then differencing the two to obtain high-resolution information. It is indeed such a setup that we have evaluated here.

[33] Regarding the upscale climate information, is an ensemble of AOGCMs always preferable to a single AOGCM, however skillful? That would appear to be the case for historical climates at least, as individual models may have been fine-tuned to perform well over different world regions, besides each one having different process-level strengths and weaknesses. Indeed, in a regional climate detection and attribution study over the western U.S., Pierce et al. [2009] demonstrated that the multimodel average (of at least 5 different global models) outperformed that of any single model on 42 different metrics, and that this is not simply due to the greater number of realizations involved, but the different modeling approaches taken.

[34] It is questionable though whether the same rationale holds when it comes to future climate projections. Especially for the 3-dimensional, time-varying fields of parameters such as winds and relative humidity, wherein the average is likely just as uncertain as the individual members.

[35] In conclusion, as the resolution (grid increment) gap between AOGCMs and RCMs continues to narrow, the matter in question of added value to climate change projections by dynamical downscaling has become more pertinent than ever. The current case study has demonstrated that the RCM skill is strongly limited by the skill of the AOGCM itself, and that skill in reproducing climatological mean conditions is not closely associated with skill in capturing climate change. Therefore, the highest priority should be given to improving the long-range climate skill of AOGCMs, and evaluations should focus on changes rather than solely on climatologies.

[36] Acknowledgments. This research was fully supported by NASA on an Applied Sciences Grant. We thank the three (anonymous) reviewers who helped improve the manuscript.

\section{References}

Brasseur, G. P., and E. Roeckner (2005), Impact of improved air quality on the future evolution of climate, Geophys. Res. Lett., 32, L23704, doi:10.1029/2005GL023902.

Castro, C., R. Pielke Sr., and G. Leoncini (2005), Dynamical downscaling: Assessment of value retained and added using the Regional Atmospheric Modeling System (RAMS), J. Geophys. Res., 110, D05108, doi:10.1029/ 2004JD004721.

Chen, F., and J. Dudhia (2001), Coupling an advanced land surfacehydrology model with the Penn State-NCAR MM5 modeling system. Part I: Model implementation and sensitivity, Mon. Weather Rev., 129(4), 569-585.

Chuang, H., G. Manikin, and R. Treadon (2001), The NCEP Meso Eta Model Post Processor: A documentation, Off. Note 438, NOAA, Silver Spring, Md. [Available at http://www.emc.ncep.noaa.gov/mmb/papers/ chuang/1/OF438.html.]

Collins, W., et al. (2004), Description of the NCAR Community Atmosphere Model (CAM 3.0), NCAR Tech. Note NCAR/TN-464+STR, NCAR, Boulder, Colo.

Davies, H., and R. Turner (1977), Updating prediction models by dynamical relaxation: An examination of the technique, $Q$. J. R. Meteorol. Soc., 103(436), 225-245.

di Luca, A., R. de Elía, and R. Laprise (2011), Potential for added value in precipitation simulated by high-resolution nested Regional Climate Models and observations, Clim. Dyn., 1, 1-19.

Fall, S., A. Watts, J. Nielsen-Gammon, E. Jones, D. Niyogi, J. Christy, and R. Pielke Sr. (2011), Analysis of the impacts of station exposure on the U.S. Historical Climatology Network temperatures and temperature trends, J. Geophys. Res., 116, D14120, doi:10.1029/2010JD015146.

Feser, F., B. Rockel, H. von Storch, J. Winterfeldt, and M. Zahn (2011), Regional climate models add value to global model data: A review and selected examples, Bull. Am. Meteorol. Soc., 92, 1181-1192.

Hong, S., and J. Lim (2006), The WRF single-moment 6-class microphysics scheme (WSM6), J. Korean Meteorol. Soc., 42(2), 129-151.

Hong, S., J. Dudhia, and S. Chen (2004), A revised approach to ice microphysical processes for the bulk parameterization of clouds and precipitation, Mon. Weather Rev., 132(1), 103-120.

Hong, S., Y. Noh, and J. Dudhia (2006), A new vertical diffusion package with an explicit treatment of entrainment processes, Mon. Weather Rev., 134(9), 2318-2341.

Jacobson, M. (2001a), GATOR-GCMM: A global- through urban-scale air pollution and weather forecast model: 1 . Model design and treatment of subgrid soil, vegetation, roads, rooftops, water, sea ice, and snow, J. Geophys. Res., 106(D6), 5385-5401.

Jacobson, M. (2001b), GATOR-GCMM: 2. A study of daytime and nighttime ozone layers aloft, ozone in national parks, and weather during the SARMAP field campaign, J. Geophys. Res., 106(D6), 5403-5420.

Jacobson, M. (2008), On the causal link between carbon dioxide and air pollution mortality, Geophys. Res. Lett., 35, L03809, doi:10.1029/ 2007GL031101.

Kain, J. (2004), The Kain-Fritsch convective parameterization: An update, J. Appl. Meteorol., 43(1), 170-181.

Kundzewicz, Z., and E. Stakhiv (2010), Are climate models "ready for prime time" in water resources management applications, or is more research needed?, Hydrol. Sci. J., 55(7), 1085-1089.

Laprise, R., R. de Elía, D. Caya, S. Biner, P. Lucas-Picher, E. Diaconescu, M. Leduc, A. Alexandru, and L. Separovic (2008), Challenging some tenets of regional climate modelling, Meteorol. Atmos. Phys., 100(1), $3-22$.

Liang, X., K. Kunkel, and A. Samel (2001), Development of a regional climate model for US Midwest applications. Part I: Sensitivity to buffer zone treatment, J. Clim., 14(23), 4363-4378. 
Liang, X., J. Pan, J. Zhu, K. Kunkel, J. Wang, and A. Dai (2006), Regional climate model downscaling of the U.S. summer climate and future change, J. Geophys. Res., 111, D10108, doi:10.1029/2005JD006685.

Liang, X., K. Kunkel, G. Meehl, R. Jones, and J. Wang (2008), Regional climate models downscaling analysis of general circulation models present climate biases propagation into future change projections, Geophys. Res. Lett., 35(8), L08709, doi:10.1029/2007GL032849.

Lucas-Picher, P., D. Caya, R. de Elía, and R. Laprise (2008), Investigation of regional climate models' internal variability with a ten-member ensemble of 10-year simulations over a large domain, Clim. Dyn., 31(7), 927-940.

Meehl, G., C. Covey, T. Delworth, M. Latif, B. McAvaney, J. Mitchell, R. Stouffer, and K. Taylor (2007), The WCRP CMIP3 multi-model dataset: A new era in climate change research, Bull. Am. Meteorol. Soc., 88(9), 1383-1394.

New, M., M. Hulme, and P. Jones (1999), Representing twentieth-century space-time climate variability. Part I: Development of a 1961-90 mean monthly terrestrial climatology, J. Clim., 12(3), 829-856.

New, M., M. Hulme, and P. Jones (2000), Representing twentieth-century space-time climate variability. Part II: development of 1901-96 monthly grids of terrestrial surface climate, J. Clim., 13(13), 2217-2238.

Pielke, R., Sr., and R. Wilby (2012), Regional climate downscaling: What's the point?, Eos Trans. AGU, 93(5), 52, doi:10.1029/2012EO050008.

Pierce, D., T. Barnett, B. Santer, and P. Gleckler (2009), Selecting global climate models for regional climate change studies, Proc. Natl. Acad. Sci. U. S. A., 106(21), 8441-8446, doi:10.1073/pnas.0900094106.

Portmann, R., S. Solomon, and G. Hegerl (2009), Spatial and seasonal patterns in climate change, temperatures, and precipitation across the United States, Proc. Natl. Acad. Sci. U. S. A., 106(18), 7324-7329.

Schmidt, G., et al. (2006), Present-day atmospheric simulations using GISS ModelE: Comparison to in situ, satellite, and reanalysis data, J. Clim., 19(2), 153-192.

Schmidt, G., et al. (2011), Climate forcing reconstructions for use in PMIP simulations of the last millennium (v1.0), Geosci. Model Dev., 4(1), 33-45, doi:10.5194/gmd-4-33-2011.
Shindell, D., G. Faluvegi, N. Unger, E. Aguilar, G. Schmidt, D. Koch, S. Bauer, and R. Miller (2006), Simulations of preindustrial, presentday, and 2100 conditions in the NASA GISS composition and climate model G-PUCCINI, Atmos. Chem. Phys., 6(3), 4427-4459.

Shindell, D., et al. (2012), Simultaneously mitigating near-term climate change and improving human health and food security, Science, 335(6065), 183-189.

Skamarock, W., J. Klemp, J. Dudhia, D. Gill, D. Barker, W. Wang, and J. Powers (2008), A description of the Advanced Research WRF Version 3, NCAR Tech. Note NCAR/TN-475+STR., NCAR, Boulder, Colo.

Székely, G., M. Rizzo, and N. Bakirov (2007), Measuring and testing dependence by correlation of distances, Ann. Stat., 35(6), 2769-2794.

von Storch, H., H. Langenberg, and F. Feser (2000), A spectral nudging technique for dynamical downscaling purposes, Mon. Weather Rev., $128(10), 3664-3673$

Wang, W., et al. (2010), User's guide for Advanced Research WRF (ARW) Modeling System Version 3.3, UCAR, Boulder, Colo. [Available at http://www.mmm.ucar.edu/wrf/users/docs/user_guide_V3.3/.]

Wilby, R. (2010), Evaluating climate model outputs for hydrological applications, Hydrol. Sci. J., 55(7), 1090-1093.

Wilby, R., and S. Dessai (2010), Robust adaptation to climate change, Weather, 65(7), 180-185.

Wilby, R., and T. Wigley (1997), Downscaling general circulation model output: A review of methods and limitations, Prog. Phys. Geogr., 21(4), 530-548.

$\mathrm{Xu}, \mathrm{Z}$., and Z. Yang (2012), An improved dynamical downscaling method with GCM bias corrections and its validation with 30 years of climate simulations, J. Clim., 25, 6271-6286, doi:10.1175/JCLI-D-12-00005.1.

Zhang, Y. (2008), Online-coupled meteorology and chemistry models: History, current status, and outlook, Atmos Chem Phys, 8(11), 2895-2932. 